\title{
A Quantitative Study of English Verbs Conveying Falling Stock Market Situations*
}

\author{
Dong-young Lee \\ Sejong University
}

\begin{abstract}
This paper aims to investigate both the diverse verbs that convey falling stock market situations and the environments in which these English verbs occur on the basis of real data extracted from the corpus of English stock market news. This quantitative study first shows that eighteen simple verbs and twenty-one phrasal verbs are used in describing bear markets and that there are nine types (rate, amount, level, temporal adverbial, reason, degree adverbial, spatial adverbial, conjunct, and participle construction) of expressions with which these verbs co-occur in sentences of stock market news. In addition, the study reveals that there is wide variation in the occurrence environments of these verbs. Moreover, it demonstrates that some verbs are restricted even in the range of rates with which they co-occur. The restrictions on the occurrence environments of the verbs can be used as guidelines for Korean reporters writing or translating sentences for English articles about falling situations in Korean markets. Such collocational information can also help English learners use more appropriate verb phrases.
\end{abstract}

\footnotetext{
* I am very grateful to an anonymous reviewer for his/her helpful comments and suggestions.
} 
Keywords: verbs conveying bearish situations, English stock market news, types of expressions, restrictions on collocates of verbs

\section{Introduction}

Many studies have been conducted on diverse linguistic units such as lexical items (Davidse et al. 2008, Noguchi et al. 2006), constructions (Carter and McCarthy 1999; Ferguson 2001; Tottie \& Hoffmann 2006), and expressions (Couper-Kuhlen 2004; Deignan 1999) on the basis of real data drawn from corpora. There has also been some research on verbs (Ozón 2006; Rudanko 2006) among lexical items. Following these corpus-based studies on a variety of linguistic units, this paper first examines diverse English verbs used every day to express bear markets and then investigates the occurrence environment of these verbs in sentences on the basis of the empirical data drawn from the corpus of stock market news. This is the first time to explore English verbs related to falling market situations and their occurrence environments. Since stock prices or indexes change constantly in stock markets, the corpus of market news containing the information on these fluctuations is a good source for examining the behavior of these English verbs.

This paper first explores what kinds of simple verbs and phrasal verbs are used in the news on falling market situations. Some examples are as follows:

(1) a. On Tuesday, the Dow industrials slipped 5 points while the Nasdaq Composite and S\&P 500 indexes posted slight advances.

b. Frontier Airlines [FRNT] was one of the biggest decliners, sliding more than $10 \%$.

c. Stocks inched lower Friday, with the Dow industrials ending 
its three-day streak of record closes, as investors considered a weak September jobs report and a setback for General Motors. d. The broader Standard \& Poor's 500 index was down about 0.4 percent. $^{1}$

In (1a) the form slipped of the simple verb SLIP is used to express the fall of an index, and in (1b) the form sliding of the simple verb SLIDE is used to express the decline of a company's stock. On the other hand, in (1c) the form inched lower of the phrasal verb INCH LOWER is used to express the decline of stocks, and in (1d) the form was down of the phrasal verb BE DOWN is used to express the fall of an index.

The expressions that follow such verbs in a sentence vary from verb to verb. These expressions can be classified into the nine types such as rate, level, amount, reason, temporal adverbial, degree adverbial, spatial adverbial, participle construction, and conjunct. Some verbs co-occur with a fallen amount (as 5 points in (1a)), and others co-occur with a fallen rate (as more than $10 \%$ in $(1 \mathrm{~b})$ and about 0.4 percent in (1d)). This paper also investigates the behavior of these verbs in detail based on the type and frequency of the expressions occurring together with them and reveals that there is wide variation in their occurrence environments.

This quantitative analysis further reveals that some verbs are restricted even in the range of falling rates with which they co-occur and that the three verbs (FALL, SLIP, and DECLINE) have the freest environments since they co-occur with all the nine types of expressions.

\footnotetext{
${ }^{1}$ Examples are from the following sites: (a) www.nytimes.com Update: 5:48 am ET Aug. 23, 2006; (b) www.usatoday.com Update: 4:27 pm ET Oct. 5, 2006; (c) money.cnn.com Update: 6:03 pm ET Oct. 6, 2006; (d) www.boston.com Update: 5:33 pm ET Aug. 11, 2006.
} 


\section{Construction of the Corpus of Stock Market News}

The stock market news was collected on the basis of the financial news that appears on diverse websites such as www.usatoday.com, www.nytimes.com, www.boston.com, money.cnn.com, www.ft.com, www.nyse.com, and www.abc.com. The corpus of stock market news contains everyday reports on the stock markets of Asia, Europe, Australasia as well as North America as illustrated in (2).
(2) a. In Hong Kong, clothing retailer Esprit Holdings [ESHDF] lost as much as $4.4 \%$.
b. In France, similar technology weakness was evident, with declines in STMicroelectronics [STM] and Cap Gemini pressuring the CAC-40 index down $0.9 \%$ at 5,197 .
c. New Zealand's NZX-50 Index fell 0.4\%.
d. Both the Dow and the S\&P were lower throughout the morning. ${ }^{2}$

Thus, the corpus has a wide variety of news on stock market situations in many countries.

The constructed corpus contains the financial news in the period of August to November 2006 and consists of four text files, each of which covers a whole month of everyday news. The size of each file is around 50,000 words, and the total size of the corpus is 201,107 words. Since the corpus contains abundant data on diverse market situations in many regions on the earth, it offers an optimal source for investigating the behaviors of a lot of English verbs related to falling situations.

\footnotetext{
${ }^{2}$ Examples are from the following sites: (a) www.abc.com Update: 11:27 am ET Aug. 11, 2006; (b) www.usatoday.com Update: 4:01 am ET Sept. 22, 2006; (c) www.usatoday.com Update: 9:32 pm ET Nov. 15, 2006; (d) money.cnn.com Update: 5:08 pm ET Oct. 13, 2006.
} 


\section{English Verbs and Occurrence Environments}

\subsection{Verbs Related to Falling Situations}

There are many simple verbs and phrasal verbs that are used in expressing bear markets. In order to find the verbs conveying falling market situations, a tagged corpus was first obtained from the constructed corpus of stock market news by using QTag, a part-ofspeech tagger. Then all the words that are labeled as a verb in the tagged corpus were collected. From this group of verbs, only the verbs conveying bearish situations were selected on the basis of their meaning as used in their concordance, which is produced by AntConc, a concordancing software. In this procedure of extracting verbs related to falling situations, only the final step, which is to determine whether the verb in question is really used to express bearish situations in its concordance, was carried out manually.

Let us first look at simple verbs related to falling situations in stock markets:

Table 1. Simple Verbs Expressing Bear Markets

\begin{tabular}{|c|c|c|c|}
\hline $\begin{array}{c}\text { Simple } \\
\text { Verb }\end{array}$ & Form: Frequency & $\begin{array}{c}\text { Number of } \\
\text { Forms }\end{array}$ & $\begin{array}{c}\text { Frequency } \\
\text { of Verb }\end{array}$ \\
\hline \hline FALL & $\begin{array}{c}\text { fell:515, fall:28, falling:25 } \\
\text { fallen:16, falls:10 }\end{array}$ & 5 & 594 \\
\hline LOSE & lost:92, losing:6, loses:1 & 3 & 99 \\
\hline DROP & dropped:68, drop:7, dropping:6 & 4 & 82 \\
\hline SLIP & slipped:57, slipping:7, slip:6, slips:5 & 4 & 75 \\
\hline DECLINE & $\begin{array}{c}\text { declined:43, decline:12 } \\
\text { declining:7, declines:1 }\end{array}$ & 4 & 63 \\
\hline TUMBLE & $\begin{array}{c}\text { tumbled:32, tumbling:5 } \\
\text { tumble:4, tumbles:4 }\end{array}$ & 4 & 45 \\
\hline SLUMP & slumped:33, slumping:5, slump:1 & 3 & 39 \\
\hline SLIDE & slid:19, slide:7, sliding:4, slides:3 & 4 & 33 \\
\hline
\end{tabular}


56 A Quantitative Study of English Stock Market Verbs

\begin{tabular}{|c|c|c|c|}
\hline DIP & dipped:24, dips:4, dipping:3, dip:1 & 4 & 32 \\
\hline SINK & sank:13, sinks:3, sink:2 & 3 & 18 \\
\hline SHED & shed:13, shedding:4 & 2 & 17 \\
\hline SUFFER & suffered:9, suffer:5, suffering:1 & 3 & 15 \\
\hline EASE & eased:11, ease:2 & 2 & 13 \\
\hline PLUNGE & plunged:9, plunges:3, plunge:1 & 3 & 13 \\
\hline RETREAT & $\begin{array}{c}\text { retreated:5, retreat:3 } \\
\text { retreating:3, retreats:2 }\end{array}$ & 4 & 13 \\
\hline WANE & waning:4, wane:3, wanes:2 & 3 & 9 \\
\hline EBB & ebbs:3, ebbed:3 & 2 & 6 \\
\hline PLUMMET & plummeted:6 & 1 & 6 \\
\hline
\end{tabular}

As illustrated in Table 1, in total eighteen simple verbs are used in conveying bearish market situations. Most of these simple verbs have the meaning of moving downwards, but there are also verbs that have the meaning of being taken away (the verb LOSE), experiencing something unpleasant (the verb SUFFER), moving backwards (the verb RETREAT) or becoming weaker (the verbs WANE and EBB). All these meanings are related to the meaning of making a financial loss.

(3) a. But transportation stocks suffered, with the Dow Jones transportation index off nearly $3 \%$.

b. Shanghai's Composite Index retreated $1.3 \%$ to rank as the lead declining regional market. ${ }^{3}$

In (3a) the form suffered of the verb SUFFER is used to show that the stock prices of a sector fell, and in (3b) the form retreated of the verb RETREAT is used to show that an index dropped. Thus, these verbs also express the fall of a stock price or an index in stock markets.

\footnotetext{
${ }^{3}$ Examples are from the following sites: (a) www.nytimes.com Update: 7:19 pm ET Aug. 10, 2006; (b) www.usatoday.com Update: 8:18 am ET Sept. 1, 2006.
} 
Among the eighteen simple verbs, the verb FALL occurs most frequently and occupies as much as $51 \%(=594 / 1172)$ of the total frequency of simple verbs. The top five verbs in occurrence frequency (that is, FALL, LOSE, DROP, SLIP, and DECLINE) account for $78 \%(=913 / 1172)$ of the frequency of all simple verbs conveying falling market situations. This means that on average the five verbs are used in four out of five cases in which simple verbs appear to express bear markets. In particular, when the number of stocks that fell on a trading day is mentioned in the stock market news, the words loser and decliner, which are derived from the verbs LOSE and DECLINE respectively, are exclusively used to refer to a falling stock.

(4) On the broader market for equities, decliners had a 16 to 15 edge over advancers on the New York Stock Exchange, while winners and losers were evenly balanced on the Nasdaq. ${ }^{4}$

In sentence (4) the words decliners and losers mean falling stocks, whereas the words advancers and winners mean rising stocks.

Let us now consider phrasal verbs that convey falling situations in stock markets. There are four types of these phrasal verbs, depending on the particles they have as illustrated in Table 2.

Table 2. Phrasal Verbs Expressing Bear Markets

\begin{tabular}{|c|c|c|c|}
\hline $\begin{array}{c}\text { Phrasal } \\
\text { Verb }\end{array}$ & Form: Frequency & $\begin{array}{c}\text { Number of } \\
\text { Forms }\end{array}$ & $\begin{array}{c}\text { Frequency } \\
\text { of Verb }\end{array}$ \\
\hline \multicolumn{4}{|c|}{ Type 1: [V+DOWN] } \\
\hline BE DOWN & $\begin{array}{c}\text { was down: } 111 \text {, were down: } 15 \text { be } \\
\text { down: } 8 \text {, is down: } 4 \\
\text { are down: } 2 \text {, being down: } 1\end{array}$ & 6 & 141 \\
\hline TRADE DOWN & traded down:6, trading down:3 & 3 & 11 \\
\hline
\end{tabular}

\footnotetext{
${ }^{4}$ The Example is from the following site: www.usatoday.com Update: 4:36 pm ET Sept. 18, 2006.
} 
58 A Quantitative Study of English Stock Market Verbs

\begin{tabular}{|c|c|c|c|}
\hline $\begin{array}{c}\text { Phrasal } \\
\text { Verb }\end{array}$ & Form: Frequency & $\begin{array}{c}\text { Number of } \\
\text { Forms }\end{array}$ & $\begin{array}{l}\text { Frequency } \\
\text { of Verb }\end{array}$ \\
\hline & trade down:2 & & \\
\hline COME DOWN & come down:8 & 1 & 8 \\
\hline EDGE DOWN & edged down:5, edges down:2 & 2 & 7 \\
\hline GO DOWN & go down:5 & 1 & 5 \\
\hline MOVE DOWN & moved down:3 & 1 & 3 \\
\hline NUDGE DOWN & nudged down:3 & 1 & 3 \\
\hline \multicolumn{4}{|c|}{ Type 2: [V+LOWER] } \\
\hline BE LOWER & $\begin{array}{c}\text { were lower: } 16 \text {, was lower: } 2 \\
\text { be lower: } 1\end{array}$ & 3 & 19 \\
\hline EDGE LOWER & $\begin{array}{l}\text { edged lower:9, edging lower: } 1 \\
\text { edge lower: } 1 \text {, edges lower: } 1\end{array}$ & 4 & 12 \\
\hline MOVE LOWER & $\begin{array}{l}\text { moved lower: } 9 \\
\text { moving lower: } 2\end{array}$ & 2 & 11 \\
\hline INCH LOWER & inched lower:9 & 1 & 9 \\
\hline TRADE LOWER & $\begin{array}{c}\text { traded lower:3 } \\
\text { trading lower:2, trade lower: } 2\end{array}$ & 3 & 7 \\
\hline TURN LOWER & turned lower:6 & 1 & 6 \\
\hline HEAD LOWER & $\begin{array}{l}\text { heading lower:3 } \\
\text { headed lower: } 2\end{array}$ & 2 & 5 \\
\hline DRIVE LOWER & driven lower:4 & 1 & 4 \\
\hline NUDGE LOWER & nudged lower:4 & 1 & 4 \\
\hline PULL LOWER & pulled lower: 4 & 1 & 4 \\
\hline TRACK LOWER & tracking lower:4 & 1 & 4 \\
\hline \multicolumn{4}{|c|}{ Type 3: [V+OFF] } \\
\hline BE OFF & was off: 13 , were off: 4 , is off: 1 & 3 & 18 \\
\hline BACK OFF & $\begin{array}{l}\text { backed off: } 4, \text { backs off: } 1 \\
\text { back off: } 1\end{array}$ & 3 & 6 \\
\hline \multicolumn{4}{|c|}{ Type 4: [V+UP] } \\
\hline GIVE UP & gave up:5, giving up:3 & 2 & 8 \\
\hline
\end{tabular}

Among the four types of phrasal verbs, Type 1, which has the particle down, occurs most frequently. In Type 1 the phrasal verb BE DOWN occupies a whopping $79 \%(=141 / 178)$ of the total frequency of the seven verbs belonging to the type. Among these seven phrasal verbs, the two verbs, EDGE DOWN and NUDGE DOWN, are used 
when a stock price or an index falls just a little as shown in (5).

(5) a. Australia's S\&P/ASX 200 edged down $0.1 \%$.

b. The Nikkei average nudged down 0.04 percent on Friday. ${ }^{5}$

Thus, the two phrasal verbs express the market situation in which a fallen rate is very low.

In total, eleven phrasal verbs belong to Type 2, which has the particle lower. The phrasal verb BE LOWER occurs most frequently in this type. The three phrasal verbs (EDGE LOWER, INCH LOWER, and NUDGE LOWER) are used when falling situations occur very weakly in stock markets as shown in (6).

(6) a. Shares listed in Shanghai edged lower 0.3\% while Indonesia's Jakarta Composite fell 0.6\%.

b. The ISM index inched lower $0.15 \%$ in August.

c. HSBC Holdings [HBC] nudged lower $0.1 \%{ }^{6}$

The phrasal verbs in (6) convey the situations in which a falling rate of a stock or an index is just 0.3 or less percent. It follows from (5) and (6) that the verbs such as EDGE, NUDGE, and INCH are used in phrasal verbs in order to express a slight fall in bear markets.

In Type 3, which has the particle off, the phrasal verb BE OFF occurs most frequently and occupies 75\% (18/24) of the total frequency of the four phrasal verbs belonging to the type.

In the last type, which has the particle up, there is only one phrasal verb. Although the particle up appears frequently in the phrasal verbs that express rising market situations, the phrasal verb

\footnotetext{
${ }^{5}$ Examples are from the following sites: (a) www.usatoday.com Update: 4:04 am ET Sept. 21, 2006; (b) www.boston.com Update: 5:27 am ET Sept. 1, 2006.

${ }^{6}$ Examples are from the following sites: (a) www.usatoday.com Update: 12:41 am ET Oct. 16, 2006; (b) www.nytimes.com Update: 11:35 am ET Sept. 1, 2006; (c) www.boston.com Update: 12:30 am ET Oct. 16, 2006.
} 
60 A Quantitative Study of English Stock Market Verbs

GIVE UP is used to convey falling situations as shown in (7).

(7) a. Chevron Corp. gave up 42 cents.

b. The Nasdaq gave up $1.25 \%{ }^{7}$

The reason the phrasal verb can be used in expressing the fall of a stock or an index is that it has a meaning similar to that conveyed by the verb RENOUNCE.

In the four types of phrasal verbs, a total of fifteen different simple verbs that cannot express falling situations by themselves appear. Some simple verbs appear in more than one type as illustrated in Table 3.

Table 3. Verbs Appearing in Multiple Types of Phrasal Verbs

\begin{tabular}{|c|c|c|}
\hline Verb in Phrasal Verbs & Types & Frequency \\
\hline \hline BE & Type 1, Type 2, Type 3 & 178 \\
\hline EDGE & Type 1, Type 2 & 19 \\
\hline TRADE & Type 1, Type 2 & 18 \\
\hline MOVE & Type 1, Type 2 & 14 \\
\hline NUDGE & Type 1, Type 2 & 7 \\
\hline
\end{tabular}

The verb BE, which ranks first in the frequency of occurring in phrasal verbs, appears in three types, and the remaining four verbs (namely, EDGE, TRADE, MOVE, and NUDGE) appear in two types.

So far I have shown that there are various simple verbs and phrasal verbs that are used in describing falling market situations, and that the simple verb FALL and the phrasal verb BE DOWN are the two most frequently-used verbs. In addition, I have examined the verbs and particles that appear in phrasal verbs. In the next section I will analyze the behavior of these simple verbs and phrasal verbs on

\footnotetext{
${ }^{7}$ Examples are from the following sites: (a) www.boston.com Update: 8:16 pm ET Aug. 29, 2006; (b) www.usatoday.com Update: 12:00 am ET Sept. 9, 2006.
} 
the basis of their collocates in sentences.

\subsection{Occurrence Environments of Verbs}

The environments in which the verbs expressing falling stock markets occur vary from verb to verb. Some verbs mainly co-occur with a fallen rate, whereas others mainly co-occur with a fallen amount. Investigated here are the occurrence environments of these verbs on the basis of the expressions that immediately follow the verbs in sentences of stock market news. ${ }^{8}$

In order to discover the collocates of verbs, the concordances to various forms of verbs were first collected by using the concordancing software AntConc. Based on these concordances I then checked whether a form is really used as a verb in sentences. When a form is used as a noun or an adjective, it is discarded. Through this procedure of screening, the concordances in which all forms in question function as a verb were obtained. From these refined concordances all the expressions that immediately follow a verb were collected and then classified into nine type: rate, amount, level, reason, degree adverbial, temporal adverbial, participle construction, spatial adverbial, and conjunct. ${ }^{9}$

The type rate indicates the fallen percent of a stock or an index (Shares of Zi Corp. dropped as much as 20\%). The type amount, which is expressed by points or a unit of money, indicates the difference between the previous level and the fallen level (The stock closed off 26 cents). The type level, which is usually expressed by a

\footnotetext{
${ }^{8}$ The length of these expressions ranges from a single word (The index fell $0.7 \%$ ) to multiple words (The share slumped because of the latest developments in the investigation) that constitute a phrase or a clause.

${ }^{9}$ There are cases in which no words follow the verb conveying falling situations in a sentence (for example, A number of chip stocks slip). Since such cases do not have an expression that can be regarded as a collocate of a verb, they are not taken into account in this section.
} 
number, indicates the position at which a stock or an index stays (The index slid to a 2-month low). The type reason, which begins with words such as because, as, on, with, because of, and so on, shows the cause of a falling market situation (The broader Indian market ended lower as investors held back ahead of the corporate earnings season). The type degree adverbial (for example, too much, a bit, modestly, more than expected, sharply, slightly, etc.) conveys the feeling about the fallen amount (Bristol-Myers Squibb and partner Sanofi-Aventis both slipped modestly). The type temporal adverbial indicates a time point or a period in which a falling situation occurs (Shares of firms slid for a second trading day). The type participle construction conveys the situation related to a falling situation (Major stock gauges tumble, led by tech-fueled composite). The type spatial adverbial indicates the place in which a falling situation occurs (Major mining stocks fell in Sydney). Finally, the type conjunct, which is the clause starting with and, while, but, and so forth, provides further information on a market situation (The Singapore Straits Times Index was down 0.7\%, while South Korea's Kospi index was down 1.2\%).

Let us now look at which verbs related to falling market situations occur together with which type of expressions. Most of these verbs co-occur with the type, rate, amount, or level, among the nine types discussed above. ${ }^{10}$

\footnotetext{
${ }^{10}$ Although these three types are related to numerical data on the whole, they are different from each other in their concept and occurrence with the verbs that convey bearish market situations. When an index or a stock price drops from Level A to Level B, the three types are defined as follows: (fallen) rate=(Level ALevel B)/Level A, (fallen) amount=Level A-Level B, (fallen) level=Level B. In addition, there are verbs that co-occur with only one of the three types. Thus, the three types must be distinguished for the appropriate analysis of the occurrence environments of such verbs.
} 
Table 4. Three Main Collocates of Verbs

\begin{tabular}{|c|r|r|r|}
\hline \multirow{2}{*}{ Verb } & \multicolumn{3}{|c|}{ Three Main Types } \\
\cline { 2 - 4 } & Rate & Amount & Level \\
\hline \hline FALL & 235 & 156 & 64 \\
\hline LOSE & 56 & 42 & 0 \\
\hline DROP & 35 & 25 & 8 \\
\hline SLIP & 26 & 12 & 5 \\
\hline DECLINE & 27 & 5 & 2 \\
\hline TUMBLE & 18 & 4 & 3 \\
\hline SLUMP & 11 & 5 & 5 \\
\hline SLIDE & 9 & 2 & 3 \\
\hline DIP & 10 & 6 & 4 \\
\hline SINK & 9 & 3 & 0 \\
\hline SHED & 11 & 6 & 0 \\
\hline SUFFER & 0 & 6 & 0 \\
\hline EASE & 5 & 1 & 2 \\
\hline PLUNGE & 5 & 2 & 0 \\
\hline RETREAT & 1 & 0 & 4 \\
\hline EBB & 0 & 0 & 5 \\
\hline BE DOWN & 110 & 22 & 5 \\
\hline TRADE DOWN & 11 & 0 & 0 \\
\hline COME DOWN & 0 & 4 & 2 \\
\hline EDGE DOWN & 3 & 0 & 1 \\
\hline MOVE DOWN & 3 & 0 & 0 \\
\hline NUDGE DOWN & 3 & 0 & 0 \\
\hline BE LOWER & 3 & 0 & 0 \\
\hline EDGE LOWER & 3 & 1 & 0 \\
\hline INCH LOWER & 4 & 0 & 0 \\
\hline TRADE LOWER & 2 & 0 & 0 \\
\hline NUDGE LOWER & 4 & 0 & 0 \\
\hline BE OFF & 12 & 4 & 1 \\
\hline BACK OFF & 0 & 0 & 1 \\
\hline GIVE UP & 2 & 5 & 0 \\
\hline Total & 618 & 311 & \\
\hline & & & 0 \\
\hline & 3 & 0 & 0 \\
\hline
\end{tabular}

As shown in Table 4, the most frequent type of expressions with which verbs co-occur is rate. The reason for this is that the fallen 
rate of stocks or indexes in bear markets is the primary concern of worried investors, and the stock market news reflects this fact. There are twenty-six verbs that co-occur with the type rate. Some verbs take a wide range of rates as their collocates, whereas others take only a narrow range of rates. Verbs such as FALL, DROP, and BE DOWN occur together with the expression of rates that are between $0.01 \%$ and $55.6 \%$. Consequently, these three verbs are used rather freely in expressing fallen rates. On the other hand, verbs such as EASE, EDGE DOWN/LOWER, NUDGE DOWN/LOWER, and INCH LOWER co-occur with the expression of rates that are only below $0.5 \%$. Thus, these six verbs are used in describing market situations in which just a slight fall occurs. There are also verbs that co-occur with the expression of rates that are at least $2 \%$. The verbs, TUMBLE, SLUMP, and PLUNGE, belong to this group. Accordingly, these three verbs are used in expressing a rather high rate of fall in stock markets.

The three types, rate, amount, and level, are direct indicators of a change of stocks or indexes. This means that the verbs co-occurring with all these three types of expressions in the news on bear markets play a primary role in conveying falling situations. The nine simple verbs (FALL, DROP, SLIP, DECLINE, TUMBLE, SLUMP, SLIDE, DIP, and EASE) and two phrasal verbs (BE DOWN and BE OFF) have such status. Therefore, these eleven verbs are the backbone of the verbs expressing falling market situations.

There are also adverbial types of expressions that follow the verbs related to falling situations: 
Table 5. Adverbial Collocates of Verbs

\begin{tabular}{|c|c|c|c|}
\hline \multirow[b]{2}{*}{ Verb } & \multicolumn{3}{|c|}{ Adverbial Types } \\
\hline & $\begin{array}{c}\text { Degree } \\
\text { Adverbial }\end{array}$ & $\begin{array}{l}\text { Temporal } \\
\text { Adverbial }\end{array}$ & $\begin{array}{c}\text { Spatial } \\
\text { Adverbial }\end{array}$ \\
\hline FALL & 16 & 51 & 4 \\
\hline DROP & 2 & 5 & 0 \\
\hline SLIP & 3 & 9 & 5 \\
\hline DECLINE & 3 & 13 & 2 \\
\hline TUMBLE & 0 & 8 & 2 \\
\hline SLUMP & 0 & 11 & 1 \\
\hline SLIDE & 2 & 6 & 1 \\
\hline DIP & 0 & 2 & 1 \\
\hline SINK & 0 & 2 & 0 \\
\hline SUFFER & 1 & 3 & 0 \\
\hline EASE & 1 & 1 & 0 \\
\hline PLUNGE & 0 & 1 & 1 \\
\hline RETREAT & 3 & 1 & 1 \\
\hline WANE & 3 & 0 & 0 \\
\hline PLUMMET & 0 & 3 & 0 \\
\hline BE DOWN & 1 & 1 & 1 \\
\hline COME DOWN & 0 & 2 & 0 \\
\hline EDGE DOWN & 0 & 3 & 0 \\
\hline GO DOWN & 5 & 0 & 0 \\
\hline BE LOWER & 0 & 5 & 0 \\
\hline EDGE LOWER & 0 & 0 & 1 \\
\hline MOVE LOWER & 1 & 1 & 0 \\
\hline INCH LOWER & 0 & 5 & 0 \\
\hline TRADE LOWER & 0 & 1 & 0 \\
\hline TURN LOWER & 0 & 3 & 0 \\
\hline PULL LOWER & 0 & 4 & 0 \\
\hline TRACK LOWER & 0 & 4 & 0 \\
\hline BE OFF & 0 & 1 & 0 \\
\hline GIVE UP & 1 & 0 & 0 \\
\hline Total & 42 & 146 & 20 \\
\hline
\end{tabular}

The three types, temporal adverbial, spatial adverbial, and degree adverbial, provide information such as when, where, and to 
66 A Quantitative Study of English Stock Market Verbs

what degree stocks or indexes change respectively. Among the three types, the type temporal adverbial is the most frequent one with which verbs related to bear markets co-occur. The reason for this is that, since situations in stock markets change constantly, the information on the time when such change occurs is important. The five simple verbs (FALL, SLIP, DECLINE, SLIDE, and RETREAT) and the phrasal verb BE DOWN occur together with all these three types of expressions. Thus, these six verbs are freely used along with adverbial types of expressions in stock market news.

Finally, let us consider the remaining three types of expressions that are collocates of verbs expressing bear markets.

Table 6. Other Collocates of Verbs

\begin{tabular}{|c|c|c|c|}
\hline \multirow{2}{*}{ Verb } & \multicolumn{3}{|c|}{ Remaining Types } \\
\cline { 2 - 4 } & Reason & $\begin{array}{c}\text { Participle } \\
\text { Construction }\end{array}$ & Conjunct \\
\hline \hline FALL & 17 & 7 & 10 \\
\hline LOSE & 1 & 0 & 0 \\
\hline DROP & 3 & 0 & 0 \\
\hline SLIP & 2 & 3 & 6 \\
\hline DECLINE & 3 & 1 & 3 \\
\hline TUMBLE & 4 & 2 & 0 \\
\hline SLUMP & 2 & 0 & 2 \\
\hline SLIDE & 7 & 0 & 1 \\
\hline DIP & 3 & 0 & 2 \\
\hline SINK & 1 & 0 & 1 \\
\hline SUFFER & 2 & 0 & 0 \\
\hline EASE & 1 & 0 & 0 \\
\hline PLUNGE & 2 & 2 & 0 \\
\hline RETREAT & 2 & 0 & 0 \\
\hline WANE & 0 & 0 & 3 \\
\hline PLUMMET & 3 & 0 & 0 \\
\hline BE DOWN & 1 & 0 & 0 \\
\hline BE LOWER & 6 & 3 & 0 \\
\hline EDGE LOWER & 2 & 0 & 3 \\
\hline
\end{tabular}




\begin{tabular}{|c|c|c|c|}
\hline \multirow{2}{*}{ Verb } & \multicolumn{3}{|c|}{ Remaining types } \\
\cline { 2 - 4 } & Reason & $\begin{array}{c}\text { Participle } \\
\text { Construction }\end{array}$ & Conjunct \\
\hline \hline MOVE LOWER & 3 & 1 & 0 \\
\hline TRADE LOWER & 4 & 0 & 0 \\
\hline TURN LOWER & 2 & 1 & 0 \\
\hline HEAD LOWER & 4 & 0 & 0 \\
\hline DRIVE LOWER & 4 & 0 & 31 \\
\hline Total & 79 & 20 & \\
\hline
\end{tabular}

Of the three types of expressions illustrated in Table 6, the type reason has the highest frequency since the explanation about why falling situations occur helps investors have a deeper understanding of market situations. The two types participle construc-tion and conjunct provide just subsidiary or additional information on falling market situations and thus their frequency is not high. Of the twenty-four verbs shown in Table 6, only three simple verbs (FALL, SLIP, and DECLINE) co-occur with all these three types of expressions. It follows from this that the verbs related to falling situations, especially the phrasal verbs, have a tendency not to occur together with the types of expressions that provide peripheral information on bear markets.

I have so far analyzed the occurrence environment of the verbs expressing bearish situations in stock markets. The overall information about such environment of each verb is provided in Table 7: 
68 A Quantitative Study of English Stock Market Verbs

Table 7. Occurrence Environment of Each Verb

\begin{tabular}{|c|c|c|c|c|c|c|c|c|c|}
\hline \multirow[b]{2}{*}{ Verb } & \multicolumn{9}{|c|}{ Type of Collocates } \\
\hline & $\underset{\overrightarrow{0}}{\stackrel{\nabla}{0}}$ & 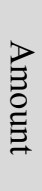 & $\begin{array}{c}\Gamma \\
\stackrel{2}{\alpha} \\
\stackrel{1}{2}\end{array}$ & 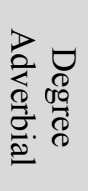 & 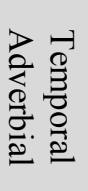 & 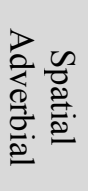 & 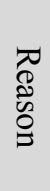 & 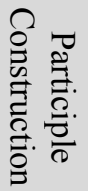 & \\
\hline FALL & O & O & 0 & o & o & o & o & o & o \\
\hline LOSE & O & O & & & & & O & & \\
\hline DROP & 0 & O & O & O & O & & O & & \\
\hline SLIP & O & 0 & O & O & O & 0 & 0 & 0 & 0 \\
\hline DECLINE & 0 & O & 0 & O & O & 0 & 0 & O & 0 \\
\hline TUMBLE & 0 & 0 & 0 & & 0 & 0 & 0 & 0 & \\
\hline SLUMP & O & O & O & & o & O & O & & O \\
\hline SLIDE & 0 & 0 & O & 0 & O & O & o & & O \\
\hline DIP & 0 & 0 & O & & O & 0 & O & & O \\
\hline SINK & 0 & 0 & & & O & & 0 & & 0 \\
\hline SHED & 0 & 0 & & & & & & & \\
\hline SUFFER & & 0 & & 0 & o & & 0 & & \\
\hline EASE & 0 & 0 & O & O & 0 & & 0 & & \\
\hline PLUNGE & 0 & 0 & & & 0 & 0 & 0 & 0 & \\
\hline RETREAT & 0 & & 0 & 0 & 0 & 0 & 0 & & \\
\hline WANE & & & & 0 & & & & & 0 \\
\hline EBB & & & O & & & & & & \\
\hline PLUMMET & & & & & o & & 0 & & \\
\hline BE DOWN & 0 & 0 & o & 0 & 0 & 0 & 0 & & \\
\hline TRADE DOWN & 0 & & & & & & & & \\
\hline COME DOWN & & O & O & & 0 & & & & \\
\hline EDGE DOWN & 0 & & 0 & & 0 & & & & \\
\hline GO DOWN & & & & 0 & & & & & \\
\hline MOVE DOWN & 0 & & & & & & & & \\
\hline NUDGE DOWN & O & & & & & & & & \\
\hline BE LOWER & 0 & & & & O & & 0 & 0 & \\
\hline EDGE LOWER & 0 & 0 & & & & o & 0 & & 0 \\
\hline MOVE LOWER & & & & 0 & O & & 0 & 0 & \\
\hline INCH LOWER & 0 & & & & O & & & & \\
\hline
\end{tabular}




\begin{tabular}{|c|c|c|c|c|c|c|c|c|c|}
\hline TRADE LOWER & $\circ$ & & & & 0 & & 0 & & \\
\hline TURN LOWER & & & & & 0 & & 0 & 0 & \\
\hline HEAD LOWER & & & & & & & 0 & & \\
\hline DRIVE LOWER & & & & & & & 0 & & \\
\hline NUDGE LOWER & $\circ$ & & & & & & & & \\
\hline PULL LOWER & & & & & 0 & & & & \\
\hline TRACK LOWER & & & & & 0 & & & & \\
\hline BE OFF & $\circ$ & $\circ$ & $\circ$ & & 0 & & & & \\
\hline BACK OFF & & & $\circ$ & & & & & & \\
\hline GIVE UP & $\circ$ & $\circ$ & & $\circ$ & & & & & \\
\hline
\end{tabular}

As illustrated in Table 7, of the thirty-nine verbs, only three (FALL, SLIP, and DECLINE) co-occur with all nine types of expressions. Thus, these three verbs are freest in the aspect of the environments in which they can occur.

On the other hand, some verbs occur together with only one type. The four verbs (TRADE DOWN, MOVE DOWN, NUDGE DOWN, and NUDGE LOWER) co-occur with only the type rate, and the two verbs (EBB and BACK OFF) occur together with only the type level. In addition, the verb GO DOWN co-occurs with only the type degree adverbial, and the two verbs (PULL LOWER and TRACK LOWER) occur together with only the type temporal adverbial. Furthermore, the two verbs (HEAD LOWER and DRIVE LOWER) cooccur with only the type reason. Accordingly, these eleven verbs are most restricted in their occurrence environment.

There are also verbs that occur together with just two types of expression (SHED co-occurring with rate and amount, WANE cooccurring with degree adverbial and conjunct, PLUMMET cooccurring with temporal adverbial and reason, and INCH LOWER co-occurring with rate and temporal adverbial). Consequently, these four verbs can be used in a very restricted environment.

Therefore, the degrees of restriction on the occurrence environment of the verbs conveying bearish market situations vary from verb to verb. There are verbs that can be used along with any of the nine 
70 A Quantitative Study of English Stock Market Verbs

types of expressions, whereas there are also verbs that can be used only in a strictly confined environment.

\section{Conclusion}

This paper has shown that in total thirty-nine verbs (eighteen simple verbs and twenty-one phrasal verbs) are used in conveying the situations in falling stock markets. The top three verbs in frequency (namely, FALL, BE DOWN, and LOSE) occupy 57\% $(=834 / 1453)$ of the total frequency. This means that on average these three verbs occur in three out of five cases in which falling market situations are described.

The phrasal verbs that express falling situations have particles such as down, lower, off, and up. The verb BE appears most frequently in these phrasal verbs. In particular, the verbs such as EDGE, NUDGE, and INCH appear in phrasal verbs when merely a slight fall occurs in stock markets. The phrasal verb GIVE UP, which is the only one that has the particle up, is also used in describing bear markets, thanks to its meaning.

The paper has also examined the occurrence environments of both simple verbs and phrasal verbs on the basis of the nine types of expressions with which these verbs co-occur. Since the three types, rate, amount, and level, provide central information on falling situations, the total frequency in the co-occurrence of the verbs with these types is much higher than that in their co-occurrence with other six types (degree/temporal/spatial adverbial, reason, participle construction, and conjunct).

Furthermore, the paper has revealed that the three verbs (FALL, SLIP, and DECLINE) have freest occurrence environment since they co-occur with all the nine types of expressions. It has also revealed that there are as many as eleven verbs (TRADE DOWN, MOVE DOWN, NUDGE DOWN, NUDGE LOWER, EBB, BACK OFF, GO 
DOWN, PULL LOWER, TRACK LOWER, HEAD LOWER, and DRIVE LOWER) that take only one type of expression as their collocate and that there are four verbs (SHED, WANE, PLUMMET, and INCH LOWER) that take just two types of expressions as their collocate.

In particular, six verbs (EASE, EDGE DOWN/LOWER, NUDGE DOWN/LOWER, and INCH LOWER) occur together with the expression of rates that are only below $0.5 \%$. On the other hand, three verbs (TUMBLE, SLUMP, and PLUNGE) occur together with the expression of rates that are at least $2 \%$. Thus, these two groups of verbs are in complementary distribution when the rate type of expression is used in sentences of stock market news.

Therefore, this paper has provided a clear explanation regarding a wide variation in the degree of restriction on the occurrence environments of verbs.

The result of quantitative analyses we have done in this paper is practically useful in that when Korean reporters and translators know the restrictions on the type of expressions with which each of the diverse English verbs related to bear markets can co-occur, they can avoid making the mistake of writing awkward verb phrases (for example, ${ }^{*}$ ebbed nearly 15 points, ${ }^{*}$ plunged almost $0.9 \%,{ }^{*}$ waned to a 3-week low, "nudged down as much as $2.4 \%$, etc.) in English articles on falling situations in Korean markets. Thus, detailed knowledge of these restrictions enables Korean people to use appropriate verbs in translating Korean reports on stock markets into English.

Moreover, the knowledge about the constraints on the collocates of these verbs can lead English learners to the appropriate and refined use of verb phrases.

\section{References}

Carter, R. \& M. McCarthy. 1999. The English Get-passive in 
72 A Quantitative Study of English Stock Market Verbs

Spoken Discourse: Description and Implication for an Interpersonal Grammar. English Language and Literature 3.1, 41-58.

Couper-Kuhlen, E. 2004. Analyzing Language in Interaction: The Practice of Never Mind. English Language and Linguistics 8.2, 207-237.

Davidse, K., L. Brems, \& L. De Smedt. 2008. Type Noun Uses in the English NP: A Case of Right to Left Layering. International Journal of Corpus Linguistics 13.2, 139-168.

Deignan, A. 1999. Linguistic Metaphors and Collocation in Nonliterary Corpus Data. Metaphor and Symbol 14.1, 19-36.

Ferguson, G. 2001. If You Pop over There: A Corpus-based Study of Conditionals in Medical Discourse. English for Specific Purposes 20.1, 61-82.

Noguchi, J., T. Orr, \& Y. Tono. 2006. Using a Dedicated Corpus to Identify Features of Professional English Usage: What Do "we" Do in Science Journal Articles? In A. Wilson, D. Archer, \& P. Rayson (eds.), Corpus Linguistics around the World 155-166. New York: Rodopi.

Ozón, G. 2006. Ditransitives, the Given Before New Principle, and Textual Retrievability: A Corpus-based Study Using ICECUP. In Antoinette R. \& A. Kehoe (eds.), The Changing Face of Corpus Linguistics 243-262. New York: Rodopi.

Rudanko, J. 2006. Emergent Alternation in Complement Selection: The Spread of the Transitive into -ing Construction in British and American English. Journal of English Linguistics 34.4, 312-331.

Tottie, G. \& S. Hoffmann. 2006. Tag Questions in British and American English. Journal of English Linguistics 34.4, 283-311.

\footnotetext{
Dong-young Lee

Department of English Language and Literature, Sejong University

98 Gunja-dong, Seongdong-gu, Seoul 143-747, Korea

Phone: +82-(0)2-3408-3636; Email: dylee@sejong.ac.kr

Received in Nov, 2009; Reviewed in Dec, 2009; Revised version received in Feb, 2010
} 